\title{
Component Assessment Data Requirements from Creep-Fatigue Tests
}

\begin{abstract}
Typically, the lifetime assessment of high temperature components, for which both creep and fatigue are principal damage mechanisms, involves (1) the determination of the stress/strain state at critical locations and (2) a numerical evaluation of the consequential damage condition. Until recently, there has not been a standard procedure specifically covering creep-fatigue testing practices. Creep-fatigue tests had been performed for many years, but the reliability and the form of the information generated was dependent on the expertise and specific interests of individual test laboratories. This situation is now resolved by the publication of a new ASTM standard based on an Electrical Power Research Institute (EPRI) led initiative. The way in which the guidance contained in this new standard specifically aims to provide creep-fatigue data requirements for defect-free component assessment is examined. Cyclic/hold tests, usually involving a simple cycle shape representative of the service transients experienced by the target component, are particularly informative in the provision of data to indicate the concurrent influences of cyclic loading on creep deformation characteristics and creep deformation on cyclic plastic response. The crack initiation endurances of such tests also provide the basis of creep-fatigue damage summation representations for a given material. Sequential creep-fatigue testing can be used to quantify the effects of prior cyclic deformation on creep rupture or prior creep deformation on fatigue endurance. The use of such test methods is also considered.
\end{abstract}

KEYWORDS: creep-fatigue interaction, testing, defect-free assessment

\section{Nomenclature}

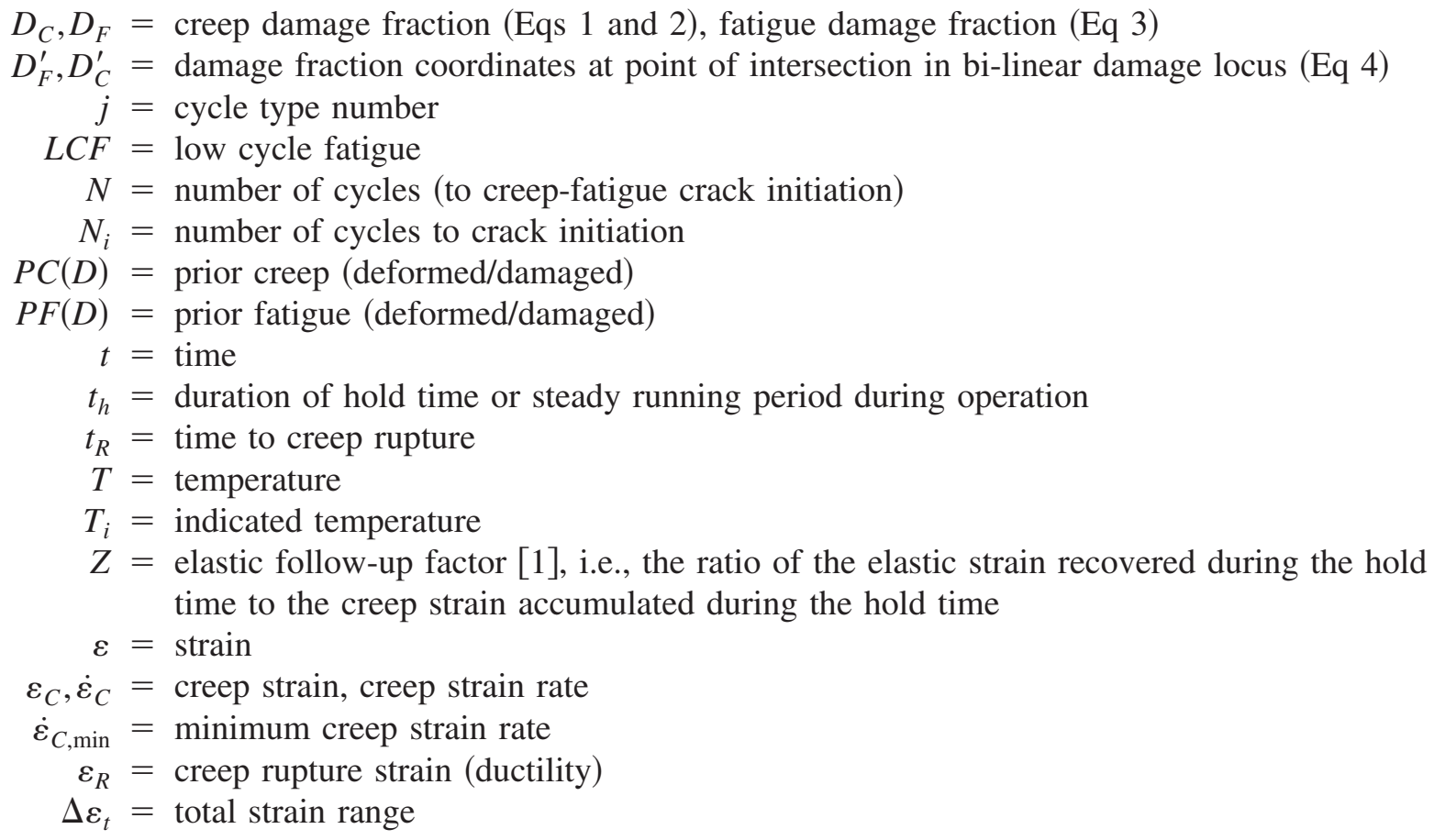

\footnotetext{
Manuscript received November 16, 2010; accepted for publication February 14, 2011; published online March 2011.

${ }^{1}$ EMPA: Swiss Federal Laboratories for Materials Science and Technology, Überlandstrasse 129, 8600 Dübendorf, Switzerland, e-mail: stuart.holdsworth@empa.ch
} 


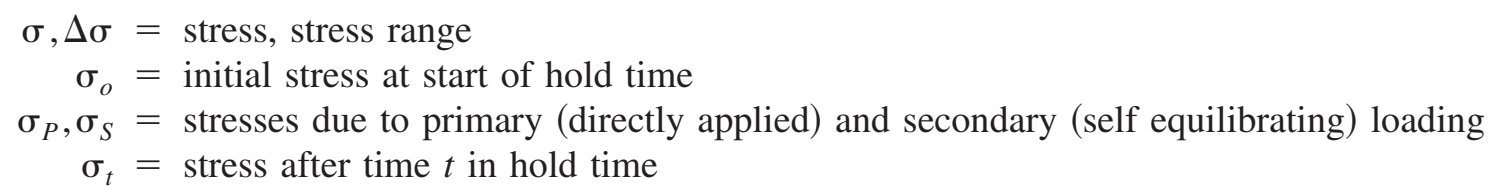

\section{Introduction}

Critical locations in high temperature power plant components may be subject to the combined accumulation of cyclic damage arising from strain transients generated during start-up and shut-down operation, and creep damage arising from primary (directly applied) and secondary (self equilibrating) stresses during operation. The development of creep-fatigue damage in most power plant steels depends on temperature, strain range, strain rate, hold time, and the creep strength and ductility of the material [2-4]. In the absence of a significant hold time (or at relatively high strain rates, or both), crack initiation and growth are fatigue dominated, even at high application temperatures (Fig. 1(a)). With increasing hold time (or decreasing strain rate, or both) at high temperatures, the creep damage condition within the structure becomes increasingly influential, to the limit beyond which crack development becomes fully creep dominated (Fig. $1(b))$. At intermediate hold times and strain rates, fatigue cracking interacts with creep damage, developing "simultaneously" or "consequentially," resulting in accelerated crack propagation (Fig. 1(c) and 1(d)). The extent of any interaction increases with decreasing creep ductility [3]. Creep-fatigue deformation interactions are also influential, and in a dominant way for a number of alloys under certain conditions [5].

Depending on the component type and the purpose of the analysis, a defect-free or defect assessment procedure (or both) is undertaken to assess fitness for service at high temperatures. Defect-free assessment procedures are commonly used for design purposes whereas defect assessment procedures are used for inspection management and remaining life evaluations, although there are exceptions to this generality. For example, there can be circumstances when it is necessary to conduct defect assessment as part of a design strategy, such as for cast components and weld containing structures. Defect-free assessment procedures to assess the tolerance of high temperature components to thermo-mechanical loading rely on the availability of creep-fatigue test data for the material(s) of construction. These data may be the result of (a) concurrent or (b) sequential creep and fatigue loading campaigns. Examples of (a) are high temperature lowfrequency triangular or saw-tooth waveform tests, or cyclic/hold tests (Fig. 2).

The focus of this paper is on those data requirements for the defect-free assessment of high temperature components, which can be determined from creep-fatigue tests.

(a) Fatigue dominated

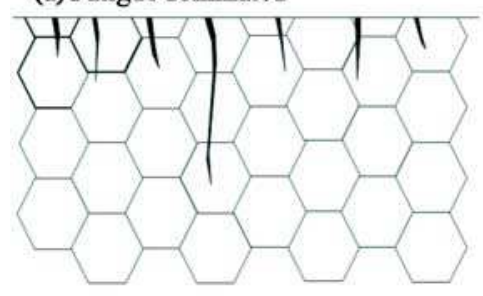

(c) Creep-fatigue interaction

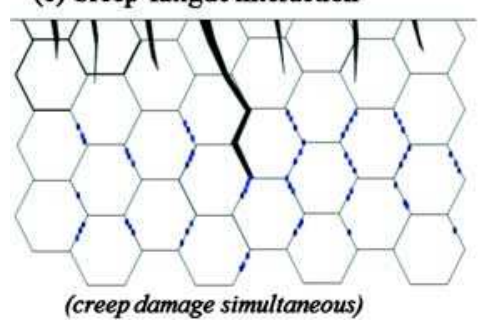

(b) Creep dominated

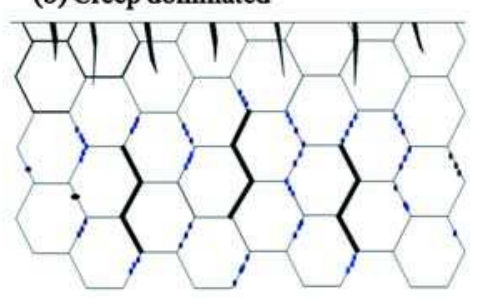

(d) Creep-fatigue interaction

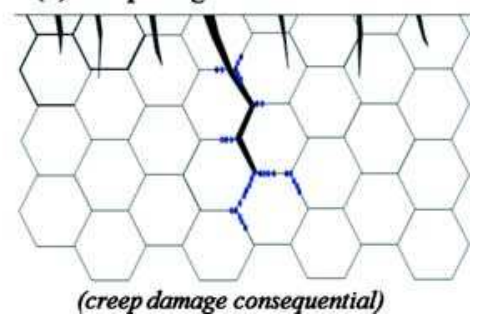

FIG. 1-Creep-fatigue cracking mechanisms: (a) Fatigue dominated, (b) creep dominated, (c) creepfatigue interaction (due to "simultaneous" creep damage accumulation), and (d) creep-fatigue interaction (due to "consequential" creep damage accumulation). 


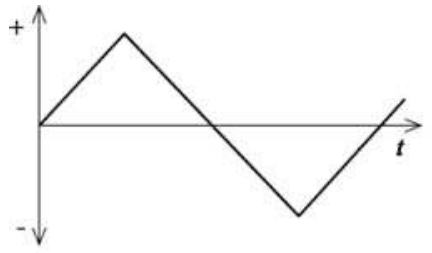

(a) Low frequency triangular wave form

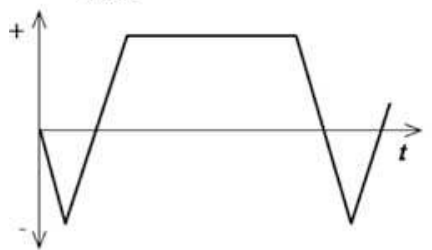

(c) Cycle with hold time at control parameter peak in tension

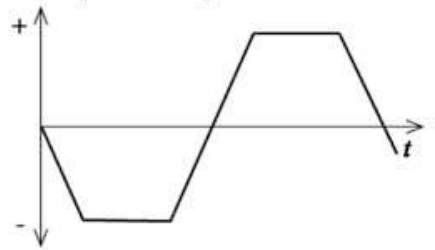

(e) Cycle with hold times at control parameter peaks in tension and compression

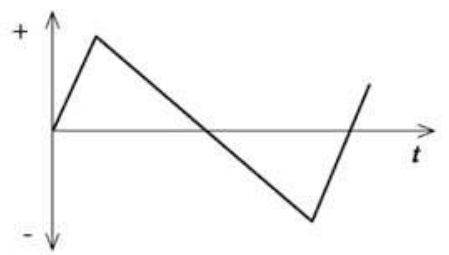

(b) Saw-tooth triangular wave form

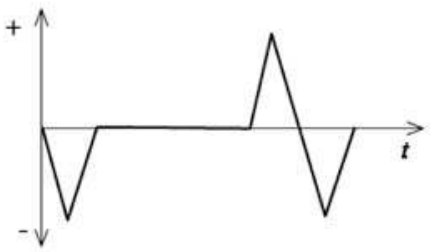

(d) Cycle with hold time at intermediate position of control parameter

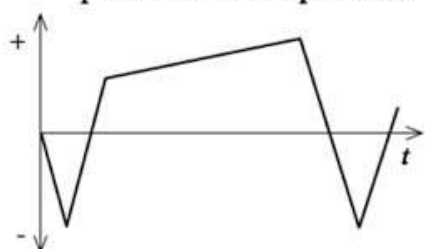

(f) Cycle with hold time controlled with different parameter(s) to that used in transient

FIG. 2-Creep-fatigue test cycle shapes.

\section{Creep-Fatigue Assessment of Defect-Free Components}

\section{Overview}

Various published and in-house procedures are adopted to assess the integrity of defect-free components subject to creep-fatigue loading, which can be represented by the generic flow diagram shown in Fig. 3 [1,6-8]. Other approaches are possible (e.g., Refs 9-11), but are not so widely adopted. An important step in all creep-fatigue assessment procedures is the determination of the state of stress and strain at critical locations in the component. This requires knowledge of the external forces and thermal transients experienced by the component during service and representations of cyclic and creep deformation properties of the material(s) of construction. The magnitudes of stresses and strains generated during thermal transients depend largely on the physical properties of the material at the critical location, such as coefficient of expansion, thermal conductivity, and elastic modulus. Irrespective of whether the local stress/strain state is determined by approximate analytical solutions or finite element analysis, the test sources of material property data are generally the same [12]. Having established the stress/strain state history at critical locations, cyclic and creep damage fractions are determined by reference to the appropriate material endurance property data (Fig. 3). The $D_{F}$ and $D_{C}$ fractions are finally compared with, for example, the crack initiation locus in a creep-fatigue damage summation diagram, and the risk of cracking is evaluated.

\section{Determination of Local Stress/Strain State}

Analysis options to determine the state of stress and strain at critical locations vary from simplified-elastic (for structures that can be shown to operate in shakedown [1]) to evolutionary full-inelastic, requiring a detailed description of deformation as a function of temperature, strain rate, and any metallurgical changes leading to hardening or softening relative to monotonic behaviour (e.g., Fig. 4). At one analytical extreme, steady-state cyclic and creep deformation are assumed, with time independent plasticity and creep behaviour being clearly distinguished. However, alternative approaches range in increasing complexity to the adoption of fully unified state variable constitutive material models (e.g., Ref 13).

When global shakedown can be demonstrated, simplified models of analysis can be used. The cyclic stress-strain behaviour at areas of local plasticity may be determined using an elastic-plastic $\Delta \sigma\left(\Delta \varepsilon_{t}\right)$ 


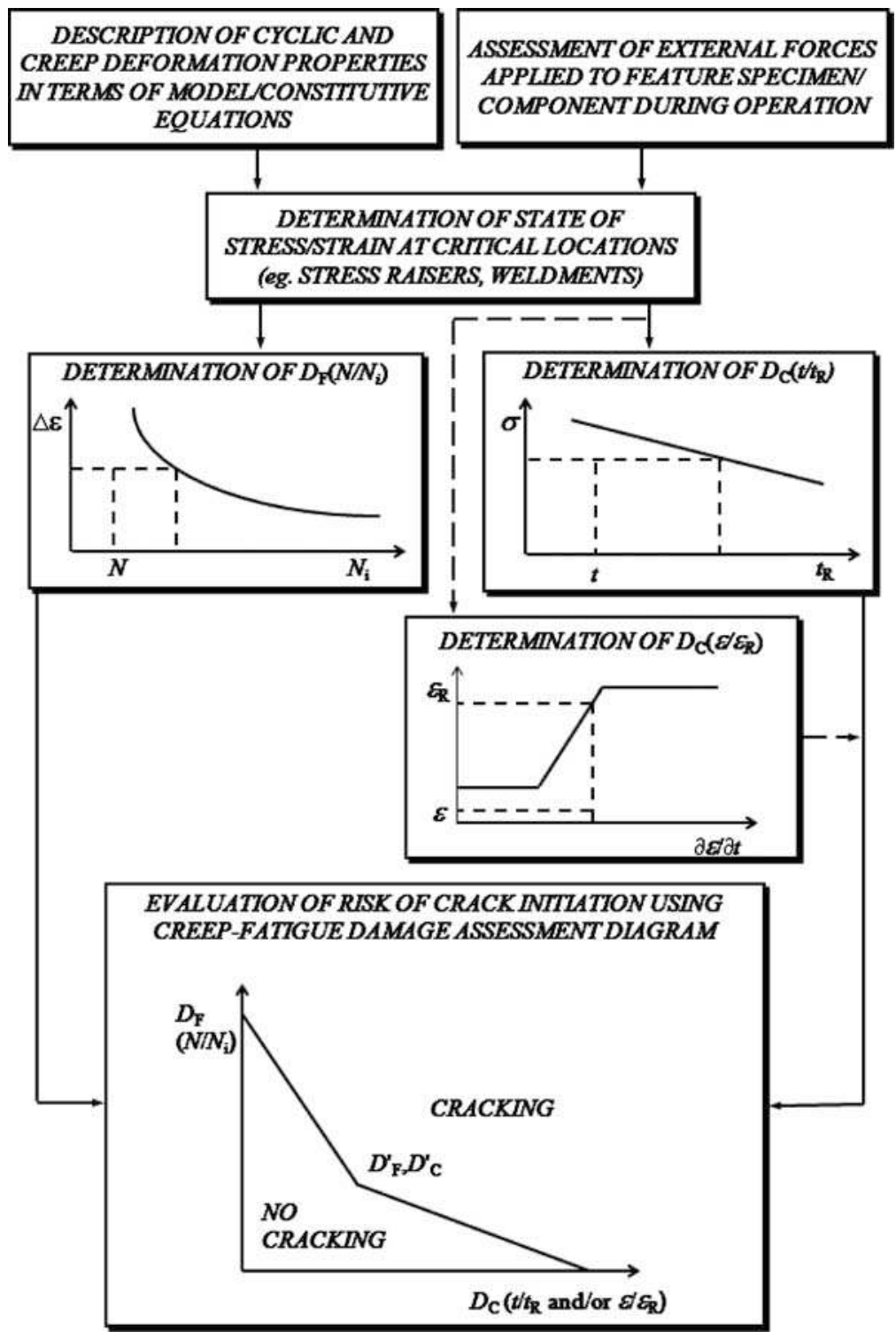

FIG. 3-Generic flow diagram representing analysis route adopted by a number of "defect-free" creepfatigue assessment procedures (e.g., Refs 1 and 6-8).

relationship for a given cycle number or for steady-state (mid-life) conditions (e.g., Ref 14), in conjunction with an appropriate strain concentration model (e.g., Ref 15) and an allowance for time dependent deformation. In such circumstances, periods of steady operation leading to load-controlled creep, straincontrolled stress relaxation, or stress relaxation under the influence of elastic follow-up may be assessed using forward creep $\varepsilon_{C}(T, \sigma, t)$ model equations; e.g., Ref 16, with an appropriate hardening law and a correction for multi-axial loading (e.g., Ref 17). Alternatively, stress relaxation may be described directly, i.e., using empirical $\sigma_{t}\left(T, \sigma_{o}, t\right)$ expressions such as in Ref 18.

If shakedown cannot be demonstrated, a more detailed inelastic analysis may be necessary, which may be based on steady-state (mid-life) conditions or may represent evolutionary behaviour (e.g., Fig. 4). Irrespective of the level of complexity, it may be necessary to account for the effects of creep on cyclic stress-strain behaviour and vice versa, and this subject is examined further in later sections.

In an attempt to overcome some of the difficulties that can be associated with the preceding methods, models have been developed that use a state variable to describe the metallurgical condition of the material at any stage of the cyclic history (e.g., Fig. 4). These variables evolve according to the time-temperaturestrain history of the component. State variable models fall into two broad categories, namely, non-unified and unified models. Non-unified models retain separate equation sets for plastic and creep deformation (e.g., Ref 19). In this approach, the state variable is the accumulated plastic strain, which is incorporated 
(a)
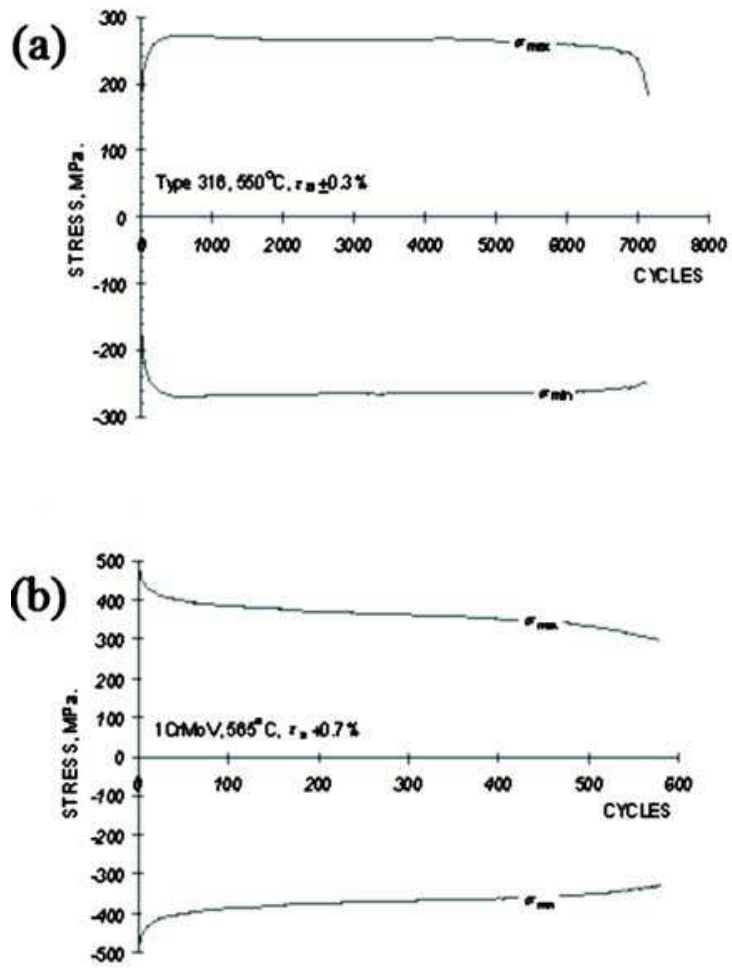
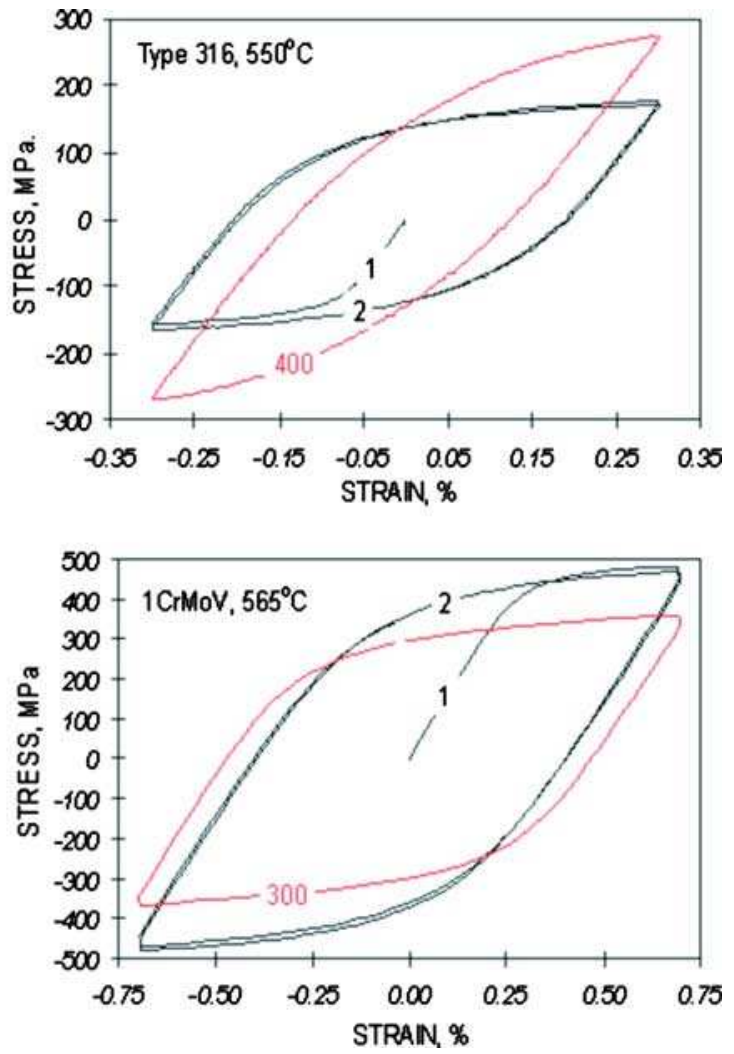

FIG. 4-Examples of (a) cyclic hardening and (b) cyclic softening behaviour in high temperature straincontrolled LCF tests.

into the creep model to reflect the effect of cyclic softening on subsequent creep deformation and into the cyclic deformation model to reflect the effect of creep softening in the plasticity model. Fully unified representations include most notably the Chaboche model [13]. Their principal feature is that they describe the stress-strain-time-temperature response of a material subjected to any combination of monotonic, cyclic, and static loading. They are visco-plastic models based on internal variables evolving with time during the inelastic deformation process. Such models are unified in that no partition or distinction is made between plastic and creep inelastic strains.

\section{Calculation of Creep-Fatigue Damage}

Creep-fatigue assessment procedures are broadly differentiated by the way the components of creep and fatigue damage are determined. As a generality, they fall into two main categories, depending on how the creep damage due to secondary (self equilibrating) loading is calculated, i.e., by time-fraction or strainfraction analysis methods. Time-fraction methods are currently the most widely used to determine the creep-fatigue damage accumulated (e.g., Refs 6-8). In any case, a time-fraction approach is always used to determine the creep usage arising from primary (directly applied) loading.

In time-fraction approaches, creep usage is determined as a function of the creep rupture time, $t_{R}(\sigma)$, i.e.,

$$
D_{C}=\sum_{j}\left\{N_{j}\left[\frac{t_{h}}{t_{R}\left(\sigma_{P}\right)}\right]\right\}+\sum_{j}\left\{N_{j}\left[\int^{t_{h}} \frac{d t}{t_{R}\left(\sigma_{S}\right)}\right]\right\}
$$

The two terms on the right side of Eq 1 respectively cover the damage accumulated due to primary and secondary loading. The creep rupture times $t_{R}\left(T, \sigma_{P}\right)$ and $t_{R}\left(T, \sigma_{S}\right)$ are determined using creep rupture strength data for the appropriate material and temperature (e.g., Ref 20).

The best known approach for the determination of creep damage in terms of strain-fraction (or ductility exhaustion) is that adopted in the $\mathrm{R} 5$ procedure [1], i.e., 


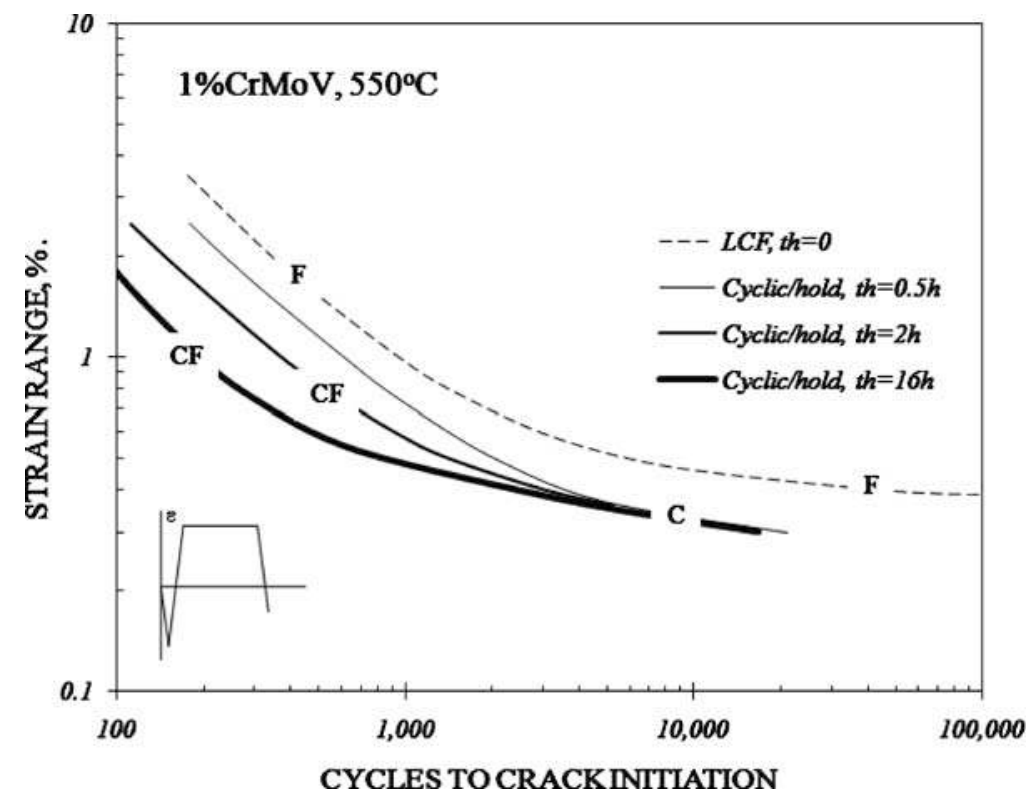

FIG. 5-Effect of increasing hold time on cyclic/hold creep-fatigue test endurance of $1 \%$ CrMoV steel at $550^{\circ} \mathrm{C}[2]$.

$$
D_{C}=\sum_{j}\left\{N_{j}\left[\frac{t_{h}}{t_{R}\left(\sigma_{P}\right)}\right]\right\}+\sum_{j}\left\{N_{j} Z_{j}\left[\int^{t_{h}} \frac{\dot{\varepsilon}_{C}}{\varepsilon_{R}\left(\dot{\varepsilon}_{C}\right)}\right]\right\}
$$

where $Z_{j}$ is the elastic follow-up factor for the $j$ th cycle type and $\varepsilon_{R}\left(\dot{\varepsilon}_{C}\right)$ characteristics are determined from the results of creep rupture tests. The consideration of ductility exhaustion is a developing area, and it has already been demonstrated that a stress modified version of the denominator in the second term on the right of Eq 2 can provide a more effective indication of the state of ductility exhaustion (e.g., Ref 21).

For the future, there are emerging energy based models for the determination of creep damage fraction (e.g., Refs 22 and 23).

Fatigue damage fraction is typically determined from a model representation of smooth specimen $N_{i}\left(\Delta \varepsilon_{t}\right)$, low cycle fatigue (LCF) crack initiation endurance data; e.g., Ref 24 , and the expression

$$
D_{F}=\sum_{j}\left\{\frac{N_{j}}{N_{i}\left(\Delta \varepsilon_{t}\right)}\right\}
$$

Some analysts account for creep damage due to secondary loading as part of the fatigue damage fraction calculation by using a $N_{i}\left(\Delta \varepsilon_{t}, t_{h}\right)$ endurance model based on observations from strain-controlled cyclic/ hold tests in Eq 3; e.g, Refs 25 and 26, this being possible when the position in the cycle and the duration of the dwell period are representative of the service application. In such circumstances, creep damage is estimated using only the first term in Eq 1 (creep damage due to secondary loading now being contained in the $D_{F}$ term). An example of the effect of hold time on cyclic/hold crack initiation endurance is shown in Fig. 5.

\section{Damage Summation}

Creep and fatigue damage may be summed with reference to a creep-fatigue damage summation diagram (Fig. 3). Bi-linear damage loci as used in Refs 1 and 6-8 may be modelled using

$$
\begin{gathered}
D_{F}=1-D_{C}\left(1-D_{F}^{\prime}\right) / D_{C}^{\prime} \quad \text { for } \quad D_{C}<D_{C}^{\prime} \\
D_{F}=\left(1-D_{C}\right) \cdot D_{F}^{\prime} /\left(1-D_{C}^{\prime}\right) \text { for } \quad D_{C}>D_{C}^{\prime}
\end{gathered}
$$

where $D_{F}^{\prime}, D_{C}^{\prime}$ defines the intersection coordinate [27]. For linear damage accumulation as in Refs 1 and 7 , $D_{F}^{\prime}, D_{C}^{\prime}=0.5$. An alternative to the bi-linear locus is the quadratic locus, which is said to represent the theoretical lower bound [28]. Apart from the quadratic representation, other damage summation options 
are determined on the basis of experimental observations from creep-fatigue tests, with $D_{F}^{\prime}, D_{C}^{\prime}$ being dependent on material, and the adopted procedures for determining the stress/strain state, and creep and fatigue damage fractions [5].

\section{Creep-Fatigue Tests}

Creep-fatigue tests performed on smooth (usually uniaxial) specimens at appropriate temperatures, strain (load) ranges, and strain (loading) rates provide the conditions for deformation and damage development due to creep-fatigue interaction (Fig. $1(c)$ and $1(d)$ ). Such tests typically involve continuous lower strain rate triangular waveform (LCF) cycles (e.g., Fig. 2(a) and 2(b)) or cyclic/hold waveforms (e.g., Fig. $2(c)-2(f))$. Until recently, there was no testing standard providing specific advice for the determination of deformation and crack initiation endurance properties under creep-fatigue loading conditions, and reliance was made upon existing guidance for LCF testing (e.g., Refs 29-31). While such publications provided the necessary information to conduct slow strain rate LCF type creep-fatigue tests, guidelines for cyclic/hold type creep-fatigue testing were not available until the publication of Ref 32 .

The new ASTM standard E2714-09 [32] originated from an Electrical Power Research Institute (EPRI) led initiative [33]. It combines the strain measurement and control (including alignment) requirements adopted for LCF testing [31] and the temperature measurement and control requirements adopted for creep and stress relaxation testing [34], to determine creep-fatigue deformation and crack initiation endurance properties. In particular, the temperature in the specimen gauge section is required to be controlled to within $\pm \max \left[2^{\circ} \mathrm{C}, 0.01 \cdot T_{i}\right]$ with due consideration to all sources of error. Specific emphasis is placed on the characterisation of damage development mechanisms through specimen post test examination.

Creep-fatigue tests may be conducted in load or strain control, although typically for the provision of data for power generation purposes they are conducted in strain control (e.g., Ref 31). Such tests are typically loaded to give crack initiation or failure endurances in the range $\sim 100$ to $<100000$ cycles. At elevated temperatures, the influence of creep processes on deformation and damage response is increased by reducing strain rate(s) during strain transients, by increasing hold times usually (but not exclusively) at peak strain in tension, or both, as shown in Fig. 2. In addition to providing crack initiation or failure endurances, for the determination of fatigue damage condition, they also provide the basis for model representations of cyclic stress-strain response throughout life.

Typically, metals subject to cyclic plastic deformation harden or soften (or both) during the course of life, by an amount depending on the temperature and the total (plastic) strain amplitude. As a generality, cyclic hardening is due to the generation and interaction of dislocations, whereas softening occurs as a consequence of dynamic recovery of the dislocation sub-structure. Many austenitic steels such as Grade 316 cyclic harden at high temperatures (Fig. 4(a)) while exhibiting both hardening and softening during the course of life at lower temperatures. In contrast, low alloy and martensitic steels such as $1 \% \mathrm{CrMoV}$ and Grade 91 cyclic soften throughout life at temperatures within their application range (Fig. 4(b)). The consequent evolution in mechanical response associated with these microstructural changes can lead to a requirement for evolutionary stress-strain representations for some applications. These are underpinned by test data, and hence the requirement for a well defined deformation data collection strategy in Ref 32 .

In addition to providing crack initiation endurance data to form the basis of damage summation relationships $[2-4,35]$, the results of creep-fatigue tests also provide data to quantify the effects of creep deformation on cyclic plasticity, and of cyclic plasticity on creep deformation.

\section{Cyclic Plastic Deformation}

The extent of cyclic softening exhibited by low alloy and martensitic steels in standard LCF tests is enhanced in creep-fatigue tests. Increasing hold times or reducing the strain rate in continuous cycle tests can have a significant influence on cyclic plastic flow response, depending on the temperature and material. For example, for Grade 91 steel, increasing hold times at peak strain in tension up to $\sim 20 \min$ is responsible for enhanced softening, although further increases appear to have little additional effect (e.g., Fig. 6). Such saturated softening profiles can be used to form the basis of evolutionary creep-enhanced cyclic plasticity models.

It appears that low alloy steels are less prone to creep-enhanced cyclic softening than martensitic steels 


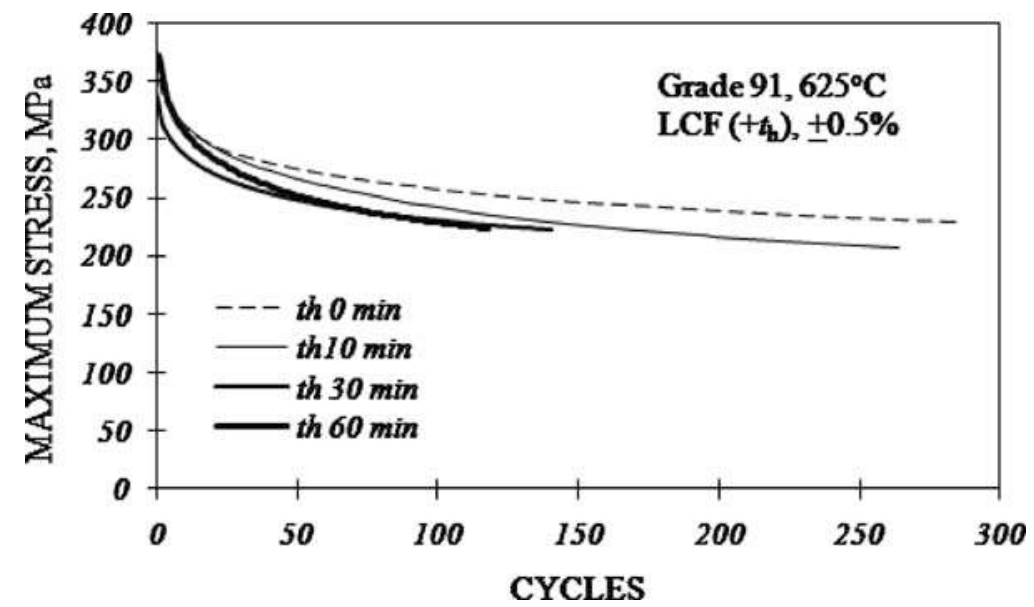

FIG. 6-Effect of increasing hold time on the extent of cyclic softening to $0.5 \cdot N_{i}$ cycles in Grade 91 steel at $625^{\circ} \mathrm{C}$.

(Fig. 7, with data from Refs 36 and 37). It also appears that the extent of this creep enhancement is greater in lower frequency continuous cycling tests than in cyclic hold tests, in particular, for the martensitic steels (Fig. 7(c) and 7(d)).

\section{Creep Deformation}

Two important considerations during the evaluation of creep response as part of creep-fatigue assessment are (1) the extent of creep softening due to cyclic plastic loading and (2) whether or not the creep process
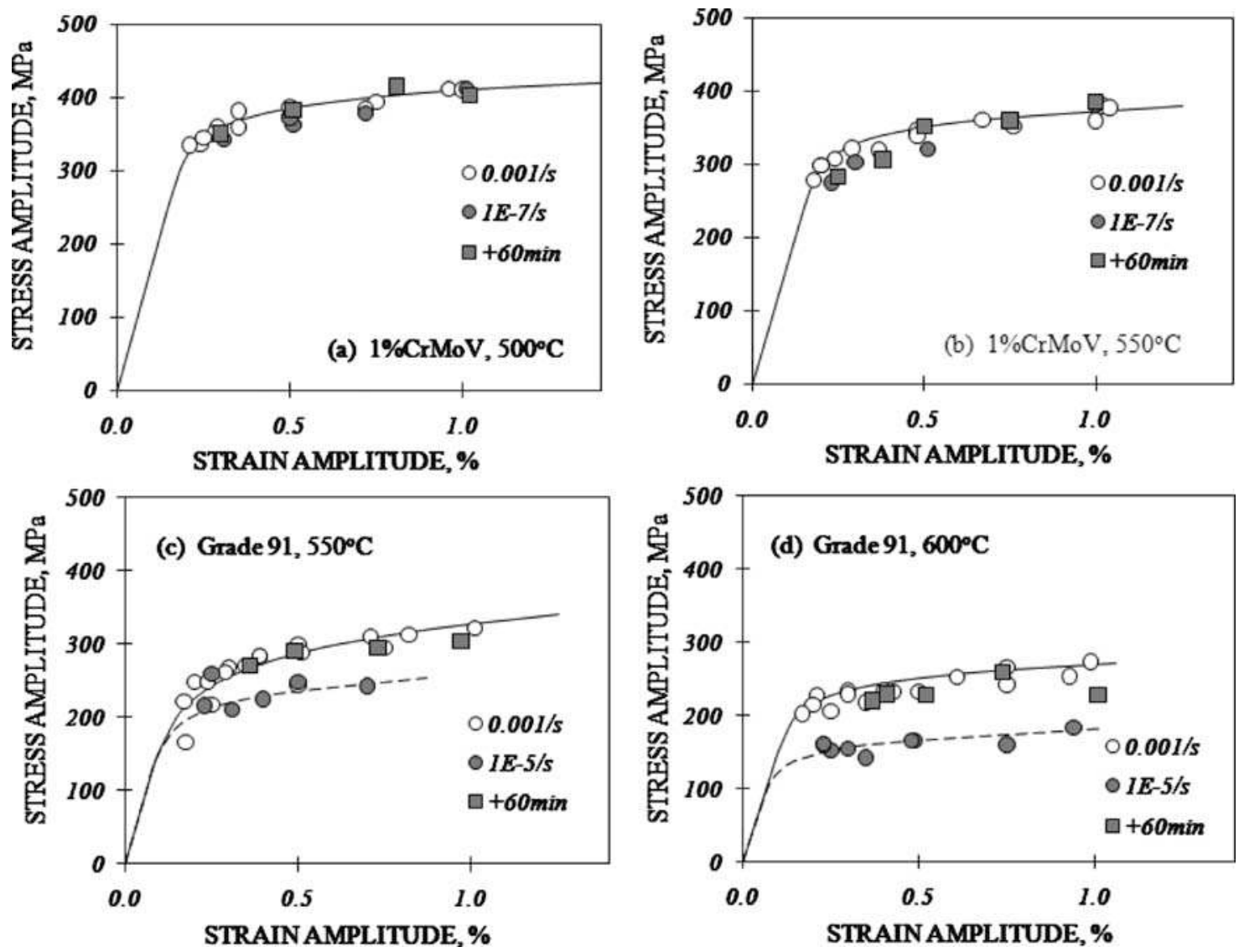

FIG. 7-Influence of reducing frequency or increasing hold time on mid-life cyclic stress-strain properties of: (a) $1 \% \mathrm{CrMoV}$ at $500^{\circ} \mathrm{C}$, (b) $1 \% \mathrm{CrMoV}$ at 550 $\mathrm{C}$, (c) Grade 91 at 550 ${ }^{\circ} \mathrm{C}$, and (d) Grade 91 at $600^{\circ} \mathrm{C}[36,37]$. 

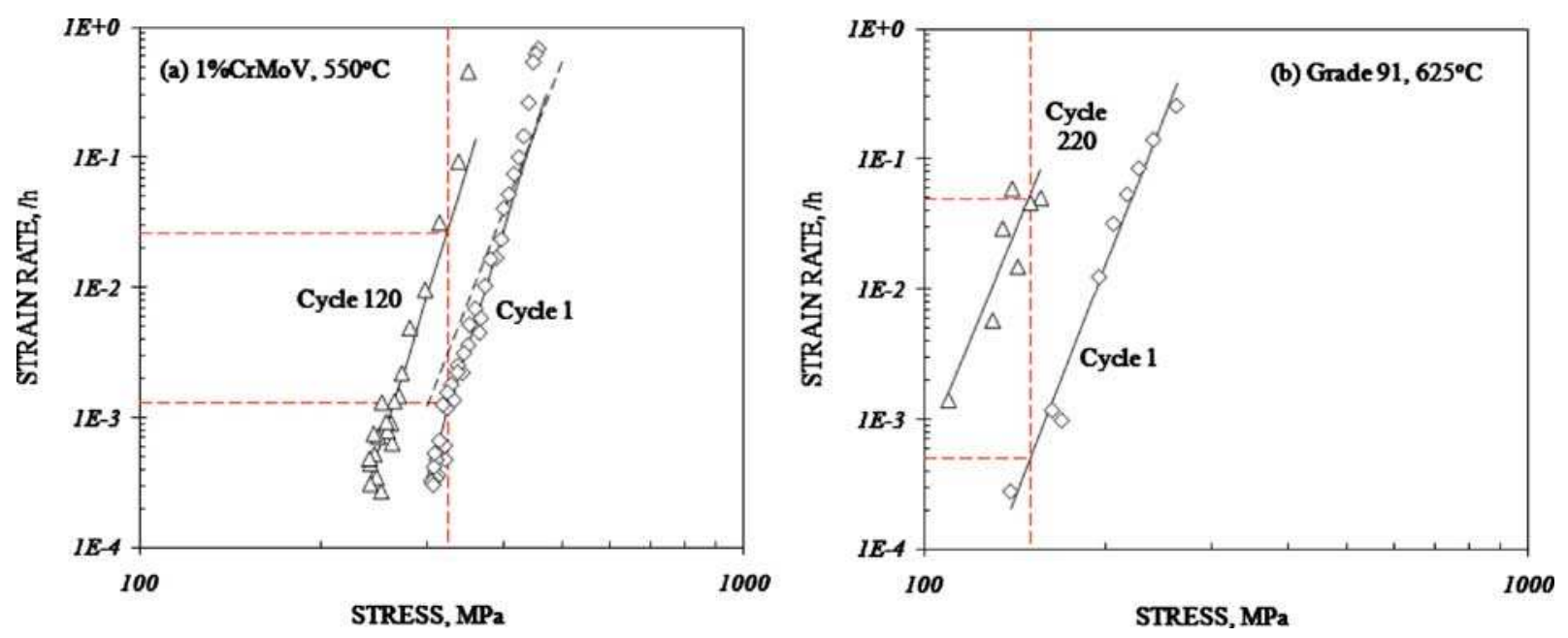

FIG. 8-Comparisons of cycle 1 and mid-life cycle $\dot{\varepsilon}_{C}(\sigma)$ profiles for $(a) 1 \% \mathrm{CrMoV}$ at $550^{\circ} \mathrm{C}$ and $(b)$ Grade 91 at $625^{\circ} \mathrm{C}$ (for test conditions: $\varepsilon_{a} \pm 0.5 \%, t_{h} 30 \mathrm{~min}$ ) [5] (the broken line in $(a)$ is the $\dot{\varepsilon}_{C, \min }(\sigma)$ line for the same heat of $1 \% \mathrm{CrMoV}$ in the virgin condition determined from the results of load-controlled creep tests).

should be re-initiated during analysis after each inelastic strain transient into compression (i.e., referred to here as primary creep persistency). Indications of the need and basis for considering both of these aspects may be determined from the results of creep-fatigue tests.

Creep Softening - Creep response is usually determined from constitutive model equations based on results from load-controlled creep rupture tests on the component material in the virgin (quality heat treated) condition. While this is invariably the only way to utilise the evidence from large data sets to realistically represent mean or minimum properties for the specified alloy (e.g., Ref 20), such model equations can only precisely represent creep during the first loading transient. Thereafter, creep response becomes dependent on cyclic history. The cyclic stress relaxation profiles from creep-fatigue tests may be used to determine $\dot{\varepsilon}_{C}(\sigma)$ characteristics as a function of cycle number (or accumulated plastic strain). Example comparisons of cycle 1 and mid-life cycle $\dot{\varepsilon}_{C}(\sigma)$ profiles for $1 \% \mathrm{CrMoV}$ and Grade 91 are shown in Fig. 8(a) and 8(b), respectively, for high application temperatures for the two steels. These illustrate the greater propensity of the martensitic steels to creep soften due to cyclic plasticity compared with low alloy ferritic steels such as $1 \% \mathrm{CrMoV}$.

Primary Creep Persistency-Following inelastic deformation in compression, some materials restart creep strain accumulation from the very beginning of the primary stage. For such materials, the creep strain calculated per cycle during creep-fatigue assessment can be significantly underestimated if this behaviour is not considered. One indication of whether a material responds in this way can be identified from the hold time $\dot{\varepsilon}_{C}(\sigma)$ profiles of creep-fatigue tests (e.g., Fig. 8), although this approach is not conclusive.

For the $1 \% \mathrm{CrMoV}$ steel shown in Fig. 8(a), it is possible to demonstrate that after an initial primary creep controlled stress relaxation phase, the $\dot{\varepsilon}_{C}(\sigma)$ characteristics determined during the hold time of the first cycle of a cyclic/hold creep-fatigue test are (as expected) almost identical to the $\dot{\varepsilon}_{C \text {,min }}(\sigma)$ properties determined from conventional load-controlled creep tests. A primary creep phase of stress relaxation is also detected at the start of the hold time of the mid-life cycle (Fig. 8(a)), and indicates the necessity to invoke primary creep persistency for this steel at this temperature. The evidence for Grade 91 in Fig. 8(b) is not so clear using this approach, and in such circumstances, it is necessary to perform cyclic creep tests involving inelastic transients in compression to clarify the position concerning primary creep persistency.

\section{Sequential Creep-Fatigue Testing}

An alternative type of creep-fatigue test is that involving the sequential application of block(s) of cyclic and steady loading to a specimen in any predefined order (e.g., Refs 38-41). They are most commonly 


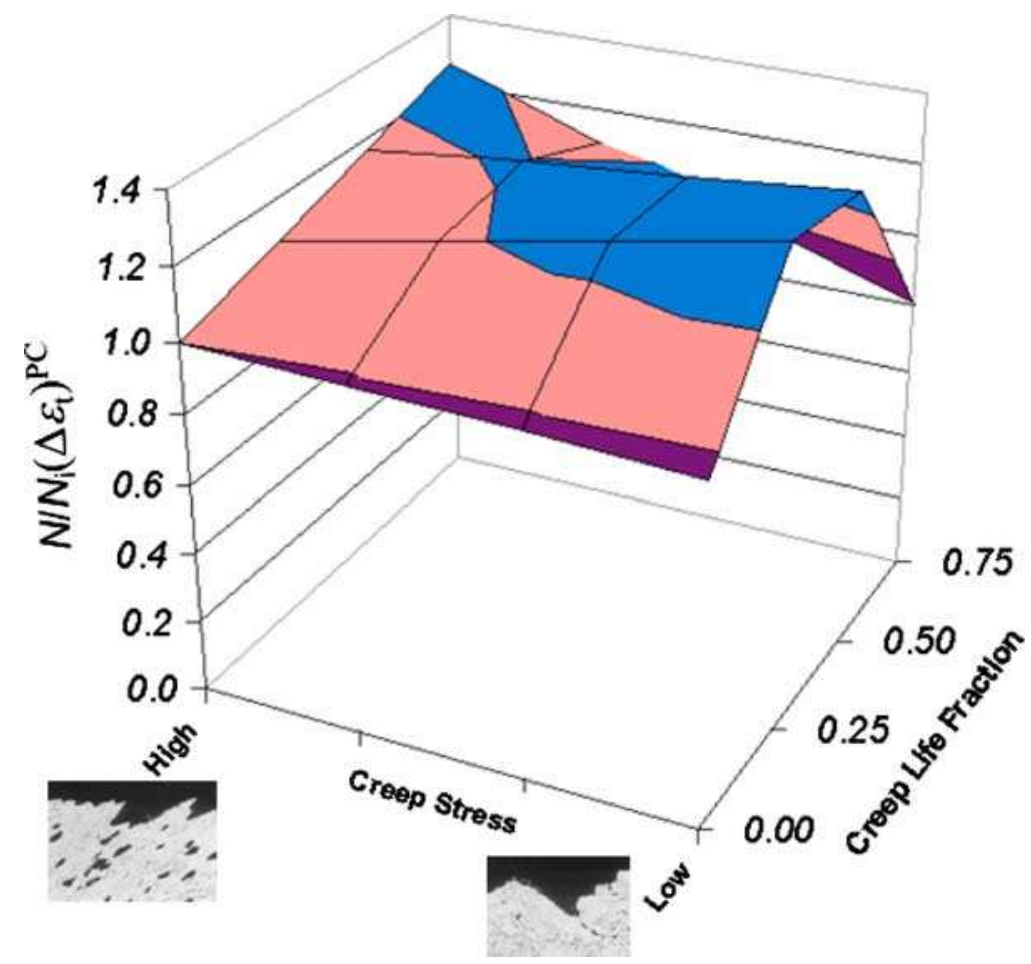

FIG. 9-Influence of stress responsible for prior creep condition on fatigue crack initiation endurance [42].

employed to represent long duration service type conditions (e.g., Refs 38 and 40) or for assessing the effect of prior creep (or fatigue) deformation on fatigue (or creep) properties, e.g., Refs 39 and 41. It has been shown that $N_{i}\left(\Delta \varepsilon_{t}\right)^{P C}$ prior creep deformed LCF crack initiation endurance data and $t_{R}(\sigma)^{P F}$ prior fatigue deformed creep rupture time data can be substituted, respectively, in Eq 3 or Eq 1 and used to construct a creep-fatigue damage summation diagram for $1 \% \mathrm{CrMoV}$ steel with coordinates that more closely relate to actual physical damage condition [5].

\section{Prior Creep Effects}

Evidence to indicate the influence of prior creep on cyclic crack initiation endurance properties for $1 \%$ CrMoV steel was systematically collected by Shinya et al. [39], and subsequently re-evaluated by Binda [42] to show that creep may have a beneficial or detrimental influence on the fatigue crack initiation resistance for this steel, depending on the deformation regime and the mechanism of damage development. Prior to the formation of physical damage, either as void particle/matrix decohesion or grain boundary cavities, fatigue crack initiation resistance is enhanced in material that has accumulated primary or secondary creep deformation. The beneficial effect of creep deformation is reversed once physical creep damage is present (Fig. 9). The point at which this occurs depends on the stress and the temperature responsible for creep and the creep ductility of the steel [3]. At higher stresses or lower temperatures (or both), significant physical creep damage is only generated relatively late in life in the form of voids due to particle/matrix decohesion, and final fracture is transgranular. In these circumstances, the fatigue crack initiation resistance continues to be enhanced until late in the creep life. At lower stresses or higher temperatures (or both), physical creep damage in the form of grain boundary cavities can occur relatively early in life when the rupture ductility is low, and later in life when the rupture ductility is higher. The development of physical creep damage at the grain boundaries has an increasingly detrimental effect on fatigue crack initiation resistance.

The numerical representation of the PCD functional surface shown in Fig. 9 enables the determination of $N_{i}\left(\Delta \varepsilon_{t}\right)^{P C}$ and substitution for $N_{i}\left(\Delta \varepsilon_{t}\right)$ in Eq 3 to determine an alternative quantity for fatigue damage fraction. 

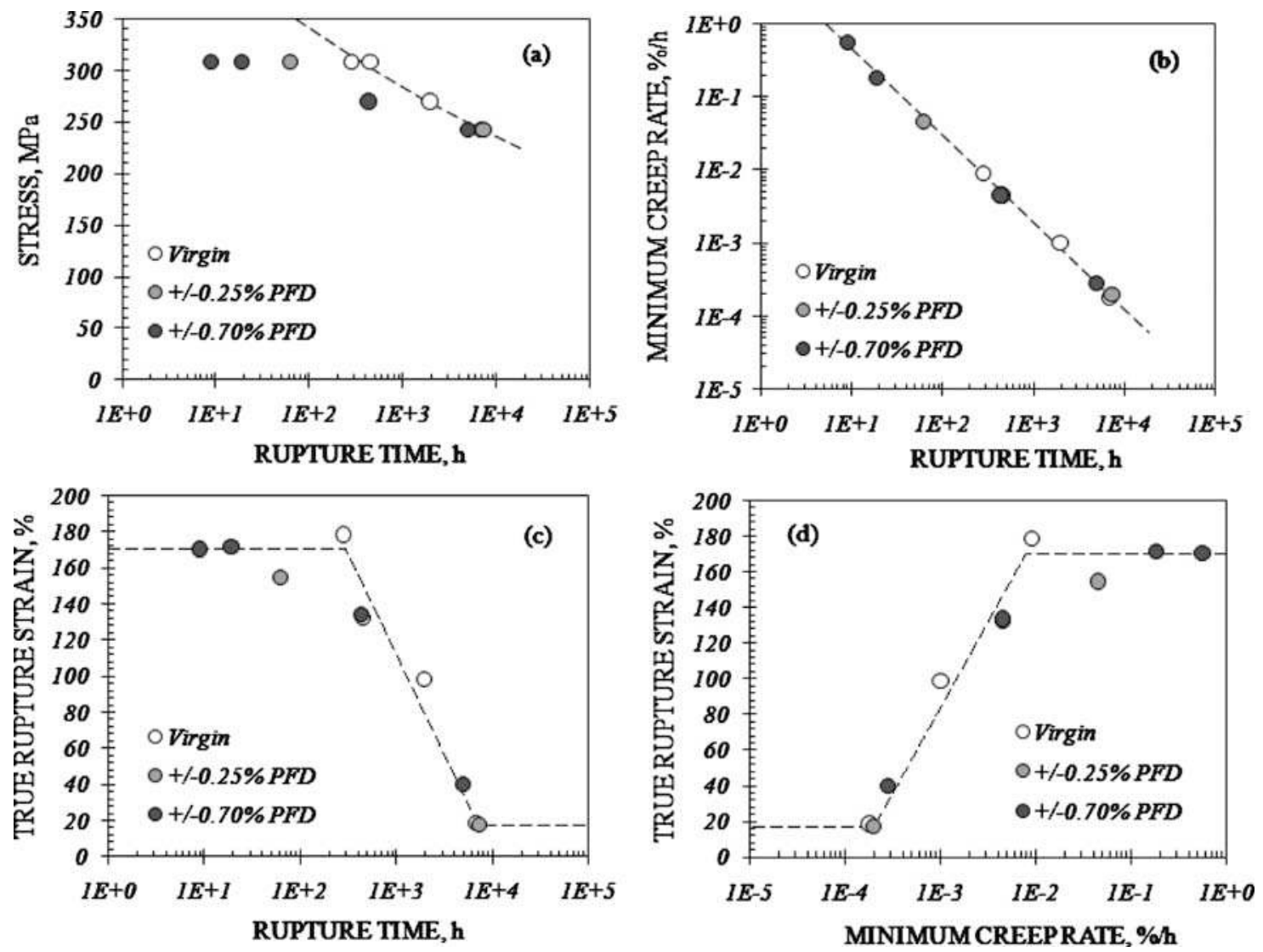

FIG. 10_Influence of prior fatigue deformation on creep rupture properties of $1 \%$ CrMoV steel [41].

\section{Prior Cyclic Deformation}

Prior cyclic deformation is responsible for cyclic softening in $1 \% \mathrm{CrMoV}$ steels, which in turn influences the magnitude of the creep strength [41]. The outcome is a reduction in rupture times and an increase in creep strain rates, but with $\dot{\varepsilon}_{C \text {, min }} t_{R}$ maintaining the same constant of proportionality as the virgin steel, Fig. $10(a)$ and 10(b) [41]. The magnitude by which the rupture time is reduced depends on the magnitude of the stress and the consequent rupture mechanism. At stress levels responsible for a ductile transgranular rupture mechanism (arising from void formation due to particle/matrix decohesion), the reduction in rupture time is significant. In contrast, at stress levels responsible for intergranular rupture (arising from grain boundary cavity formation), the reduction in rupture time is relatively small.

The effect of prior cyclic deformation on the rupture ductility of $1 \% \mathrm{CrMoV}$ steel also depends on stress and strain rate (rupture mechanism) [41]. At stresses (and strain rates) associated with lower and upper shelf rupture ductilities, the influence of prior cyclic deformation and the consequent increase in minimum creep rate is small (Fig. 10(c) and 10(d)). At stresses (and strain rates) associated with the transition from upper to lower shelf rupture ductilities, the influence of prior cyclic deformation can be responsible for a significant increase in rupture ductility.

Analytical representations of the data given in Fig. $10(a)$ and $10(d)$ enable the determination of $t_{R}(\sigma)^{P F}$ or $\varepsilon_{R}\left(\dot{\varepsilon}_{\mathrm{C}}\right)^{P F}$ or both, for substitution into $\mathrm{Eq} 1$ or Eq 2 to determine alternative quantities for creep damage fraction.

In contrast, for Grade 316 steel, the effect of prior cyclic deformation on creep is to increase the time to rupture and reduce the strain rate, with the magnitude of the effect appearing to be relatively insensitive to applied stress [42], Fig. 11. For this steel, prior cyclic deformation is responsible for a significant increase in rupture ductility at all strain rates. The effects of prior cyclic deformation on creep rupture properties are dependent on material and temperature.

The use of fatigue endurance and creep rupture models involving the results from prior creep and prior fatigue tests can provide more effective estimates of $D_{F}$ and $D_{C}$ damage fractions, which can be formu- 

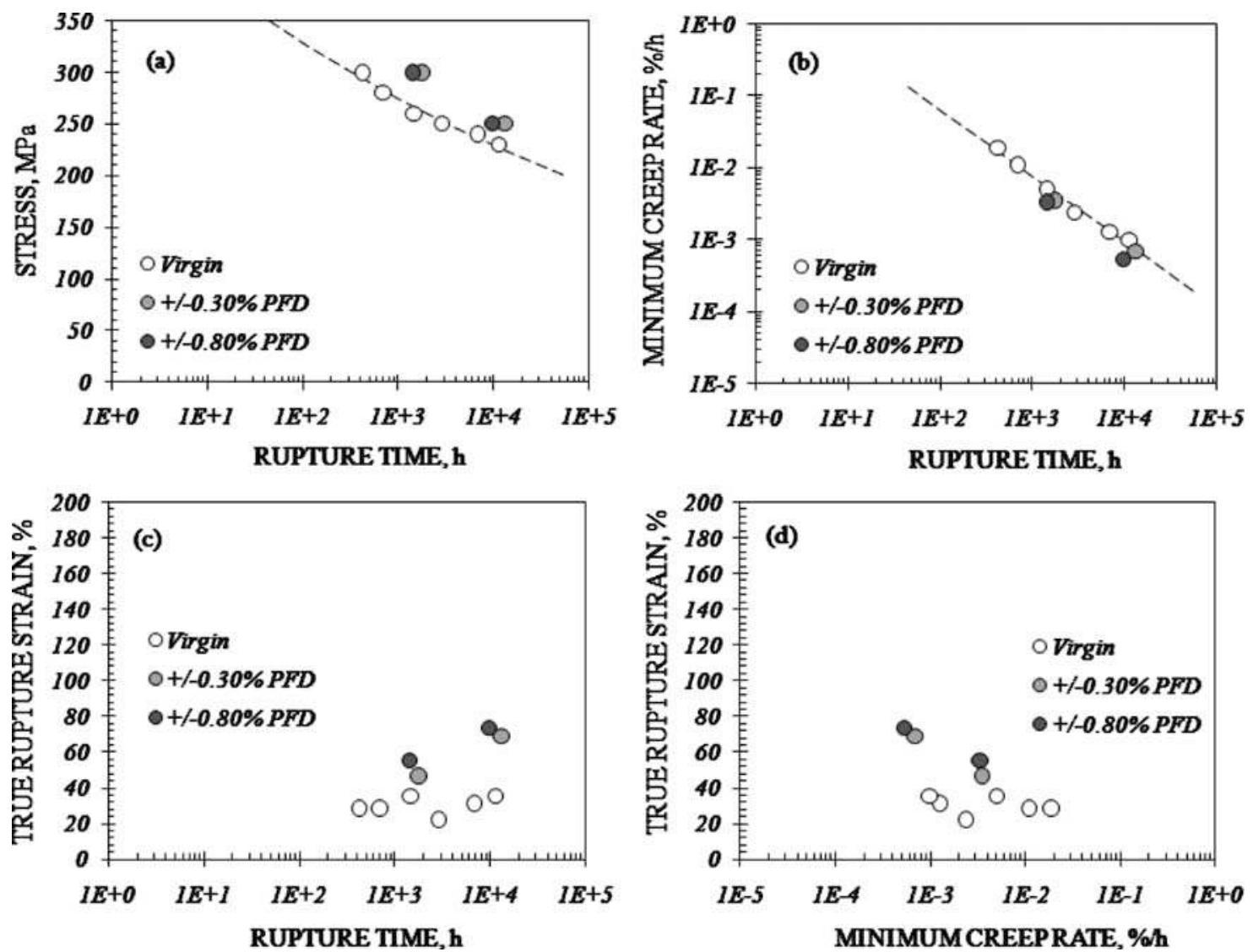

FIG. 11-Influence of prior fatigue deformation on creep rupture properties of Grade 316 steel [42].

lated in an evolutionary way [5] but requires a significantly more sophisticated material property database than currently adopted in traditional approaches (e.g., Refs 1 and 6-8). Nevertheless, such an approach provides a potential solution for the future.

\section{Concluding Remarks}

Typically, the defect-free assessment of high temperature components for which both creep and fatigue are the principal damage mechanisms involves (1) the determination of the stress/strain state at critical locations and (2) a numerical evaluation of the consequential damage condition. Creep-fatigue tests are a significant source of material input data for such assessments, and a new standard [32] provides the necessary guidance for their performance.

Cyclic/hold creep-fatigue tests are particularly informative in the provision of data to indicate the concurrent influences of cyclic loading on creep deformation characteristics and creep deformation on cyclic plastic response, in addition to crack initiation endurance data to form the basis of creep-fatigue damage summation representations.

Sequential creep-fatigue testing can also be productively used to quantify the effects of prior creep deformation on fatigue endurance and prior cyclic deformation on creep rupture (for the determination of more physically realistic fatigue and creep damage fractions for certain materials).

\section{References}

[1] R5, 2003, "An Assessment Procedure for the High Temperature Response of Structures," British Energy Generation, Ltd., Barnwood.

[2] Thomas, G. and Dawson, R. A. T., "The Effect of Dwell Period and Cycle Type on High Strain Fatigue Properties of $1 \mathrm{CrMoV}$ Rotor Forgings at $500-550^{\circ} \mathrm{C}$," Proc. Intern. Conf. on Engineering Aspects of Creep, Sheffield, Sept. 15-19, 1980, Institute of Mechanical Engineers, London, United 
Kingdom, pp. 167-173.

[3] Miller, D., Priest, R. H., and Ellison, E. G., "A Review of Material Response and Life Prediction Techniques," High Temp. Mater. Processes (N.Y., NY, U.S.), Vol. 6, Nos. 3/4, 1984, pp. 155-194.

[4] Bicego, V., Fosati, C., and Ragazonni, S., "Low Cycle Fatigue Characterisation of a HP-IP Steam Turbine Rotor," Low Cycle Fatigue, ASTM STP 942, H. D. Solomon, G. R. Halford, L. R. Kaisand, and B. N. Leis, Eds., ASTM International, West Conshohocken, PA, 1988, pp. 1237-1260.

[5] Holdsworth, S. R., "Creep-Fatigue in Steam Turbine Materials," Proc. Sixth Intern. Conf. on Advances in Materials Technology for Fossil Power Plants, Santa Fe, NM, Aug. 31-Sept. 3, 2010, EPRI/ASM.

[6] ASME, 2001, "Rules for the Construction of Nuclear Facility Components, Class 1 Components in Elevated Temperature Service, Boiler and Pressure Code, Section III, Division 1-Subsection NH," American Society of Mechanical Engineers (ASME), New York.

[7] TRD 301, 1978, “Annex I-Design: Calculation for Cyclic Loading due to Pulsating Internal Pressure or Combined Changes of Internal Pressure and Temperature, Technical Rules for Steam Boilers," Technische Regeln für Dampfkessel.

[8] RCC-MR, 1985, "Design and Construction Rules for Mechanical Components of FBR Nuclear Islands, Section I-Nuclear Islands Components," AFCEN.

[9] Halford, G. R. and Manson, S. S., "Life Prediction of Thermal Mechanical Fatigue Using Strain Range Partitioning," Thermal Fatigue of Materials and Components, ASTM STP 612, D. A. Spera and D. F. Mowbray, Eds., ASTM International, West Conshohocken, PA, 1976, pp. 239-254.

[10] Hoffelner, W., "Creep-Fatigue Life Determination of Grade 91 Steel Using Strain-Range Separation Method," Proc. ASME Pressure Vessel and Piping Conf. on Sustainable Energy for the Third Millennium, Prague, July 26-30, 2009, American Society of Mechanical Engineers (ASME), New York.

[11] Prager, M., "Extend Low Chrome Steel Fatigue Rules," Report No. STP-PT-027, ASME Standards Technology, LLC, New York, 2009.

[12] Holdsworth, S. R., "A Knowledge Based System for Creep-Fatigue Assessment," Nucl. Eng. Des., Vol. 188, 1999, pp. 289-301.

[13] Chaboche, J. L., "A Review of Some Plasticity and Viscoplasticity Constitutive Theories," Int. J. Plast., Vol. 24, No. 10, 2008, pp. 1642-1693.

[14] Ramberg, W. and Osgood, W. R., "Description of Stress Strain Curves by Three Parameters," Report No. NACE TN-902, National Advisory Committee for Aeronautics (NACE), Washington, 1943.

[15] Neuber, H., "Theory of Stress Concentration for Shear-Strained Prismatical Bodies with Arbitrary Non-Linear Stress-Strain Law," Trans. ASME (Series E), Vol. 28, 1961, pp. 544-550.

[16] Holdsworth, S. R., "Constitutive Equations for Creep Curves and Predicting Service," CreepResistant Steels, F. Abe, T.-U. Kern, and R. Viswanathan, Eds., Woodhead Publ., Cambridge, 2008, pp. 403-420.

[17] Cocks, A. F. C. and Ashby, M. R., "Intergranular Fracture During Power-Law Creep Under MultiAxial Stress," Met Sci., Vol. 14, 1982, pp. 395-402.

[18] Feltham, P., "Stress Relaxation in Copper and Alpha Brasses at Low Temperatures," Philos. Mag., Vol. 6, 1961, pp. 259-270.

[19] Mazza, E., Hollenstein, M., Holdsworth, S. R., and Skelton, R. P., "Notched Specimens ThermoMechanical Fatigue of a 1CrMoV Turbine Steel," Nucl. Eng. Des., Vol. 234, 2004, pp. 11-24.

[20] D. G. Robertson and S. R. Holdsworth, Eds., "Rupture Strength, Creep Strength and Relaxation Strength Values for Carbon-Manganese, Low Alloy Ferritic, High Alloy Ferritic and Austenitic Steels, Nickel Base Alloys and High Temperature Bolting Steels," ECCC Data Sheets, European Technical Developments (ETD), Leatherhead, 2005, http://www.ommi.co.uk/etd/eccc/ advancedcreep/open.htm.

[21] Spindler, M. W., "The Multiaxial and Uniaxial Creep Ductility of Type 304 Steel as a Function of Stress and Strain Rate," Mater. High. Temp., Vol. 21, No. 1, 2004, pp. 47-52.

[22] Takahashi, Y., "Study on Creep-Fatigue Evaluation Procedures for High Chromium Steels—Part I: Tests Results and Life Predictions Based on Measured Stress Relaxation," Int. J. Pressure Vessels Piping, Vol. 85, 2008, pp. 406-422.

[23] Payten, W. M., Dean, D. W., and Snowden, K. U., "A Strain Energy Density Method for the Prediction of Creep Fatigue Damage in High Temperature Components," Mater. Sci. Eng., A, Vol. 527, 
Nos. 7-8, 2010, pp. 1920-1925.

[24] Coffin, L. F., "A Study of the Effects of Cyclic Thermal Stresses on a Ductile Metal," Trans ASME (Series A), Vol. 76, 1954, pp. 931-950.

[25] Timo, D. P., "Designing Turbine Component in Fatigue," Proc. Intern. Conf. on Thermal Stresses and Fatigue, Berkeley, United Kingdom, September 1969, Central Electricity Generating Board, UK, pp. 453-469.

[26] Dawson, R. A. T., "Monitoring and Control of Thermal Stress and Component Life Expenditure in Steam Turbines," Proc. Intern. Conf. on Modern Power Stations, 1989, AIM, Liège.

[27] Holdsworth, S. R., "Prediction of Creep-Fatigue Behaviour at Stress Concentrations in $1 \mathrm{CrMoV}$ Rotor Steel," Proc. Conf. on Life Assessment and Life Extension of Engineering Plant Structures and Components, Churchill College, Cambridge, United Kingdom, September 1996, Engineering Materials Advisory Service, Warley, UK, pp. 137-146.

[28] Skelton, R. P. and Gandy, D., "Creep-Fatigue Damage Accumulation and Interaction Diagram Based on Metallographic Interpretation of Mechanisms," Mater. High. Temp., Vol. 25, No. 1, 2008, pp. 27-54.

[29] Thomas, G. B., Hales, R., Ramsdale, J., Suhr, R. W., and Sumner, G., "A Code of Practice for Constant-Amplitude Low Cycle Fatigue Testing at Elevated Temperatures," Fatigue Fract. Eng. Mater. Struct., Vol. 12, No. 2, 1989, pp. 135-153.

[30] Hales, R., Holdsworth, S. R., O’Donnell, M. P., Perrin, I. J., and Skelton, R. P., “A Code of Practice for the Determination and Interpretation of Cyclic Stress-Strain Data," Mater. High. Temp., Vol. 19, No. 4, 2002, pp. 165-185.

[31] ISO 12106, 2003, "Metallic Materials-Fatigue Testing_Axial Strain Controlled Method, International Organisation for Standardisation.

[32] ASTM E2714-09, 2009, "Standard Test Method for Creep-Fatigue Testing," Annual Book of ASTM Standards, Vol. 3.03, ASTM International, West Conshohocken, PA.

[33] Holdsworth, S. R. and Gandy, D., "Towards a Standard for Creep-Fatigue Testing," Proc. Fifth Intern. Conf. on Advances in Materials Technology for Fossil Power Plants, Marco Island, FL, Oct. 3-5, 2007, R. Viswanathan, D. Gandy, and K. Coleman, Eds., EPRI/ASM, pp. 689-701.

[34] EN 10319, 2003, "Metallic Materials-Tensile Stress Relaxation Testing," European Committee for Standardisation (CEN).

[35] Holdsworth, S. R., "Creep-Fatigue of High Temperature Turbine Steels," Mater. High. Temp., Vol. 18, No. 4, 2001, pp. 261-265.

[36] NRIM, "Elevated-Temperature Time-Dependent Low-Cycle Fatigue Properties of ASTM A470-8 (1Cr-1Mo-0.25V) Steel Forgings for Turbine Rotors and Shafts," NRIM Data Sheet No. 58, National Research Institute for Metals, Tokyo, Japan, 1987.

[37] NRIM, "Time-Dependent Low-Cycle Fatigue Properties of ASTM A387 Grade 91 (9Cr-1Mo) Steel Plate for Pressure Vessels," NRIM Data Sheet No. 78, National Research Institute for Metals, Tokyo, Japan, 1993.

[38] Leven, M. M., “The Interaction of Creep and Fatigue for a Rotor Steel,” Exp. Mech., Vol. 13, No. 9, 1973, pp. 353-372.

[39] Shinya, N., Kyono, J., Kushima, H., and Yokoi, S., "Effect of Creep Damage on Fatigue Life of Cr-Mo-V Steel," Trans. National Research Institute for Metals, Vol. 29, No. 2, 1987, pp. 115-123.

[40] Granacher, J. and Scholz, A., "Creep-Fatigue Resistance of Heat Resistant Steels Under Service-Type Long Term Conditions," Proc. Third Intern. Conf. on Low Cycle Fatigue and Elasto-Plastic Behaviour of Materials, Berlin, 1992, K.-T. Rie, Ed., Elsevier Appl. Sci, pp. 235-241.

[41] Binda, L., Holdsworth, S. R., and Mazza, E., "Influence of Prior Cyclic Deformation on Creep Properties of 1CrMoV," Mater. High. Temp., Vol. 27, No. 1, 2010, pp. 21-27.

[42] Binda, L., 2010, "Advanced Creep Damage and Deformation Assessment of Materials Subject to Steady and Cyclic Loading at High Temperatures," DSc thesis, Institut für Mechanische Systeme, ETH, Zürich, DISS. ETH No. 18462. 